its extreme variability and one of the most sensitive (in performance) of the whole range of petroleum distillates.

Broadly speaking, it is demanded that a highquality lubricating oil should possess a good viscosity index, a low pour point, a wide range of stability, high flash point and low earbon value; these properties are claimed as entirely characteristic of the synthetic product. A good viscosity implies an oil which changes least in characteristics with temperature range, making for easy starting of an engine in cold weather, reducing wear of the moving parts and, at the same time, ensuring that under operating conditions an adequate oil film is preserved round the piston; these factors naturally affect the question of oil consumption. The essence of stability is the ability of the oil to preserve its fundamental characteristics in performance, and the lack of tendency to form sludge or to coagulate in any manner which might tend to choke the lubricating system. The low carbon value is sought for many reasons ; chiefly to take care that, whatever carbon is formed, is of a soft and noncrystalline character, as hard carbon particles returned to the oil sump will inevitably act as an abrasive and do damage to the vital parts of the engine.

Production of modern lubricating oils is, quite apart from this new process, a highly specialised subject, concerning which much still remains to be, and is being, done in the matter of fundamental research. Possibilities of hydrogenation as applied to petroleum products have of course been long foreseen by technologists both in Great
Britain and in America, but the advent of a marketable product at this juncture is certainly a most commendable departure.

An account of this enterprising action of the Anglo-American Oil Co., the concern responsible for the introduction of this new lubricating oil, appears in the Times of April 29. Concurrently with the appearance of this product, the same Company is responsible for introducing a new method of delivery of the oil to motor engines. Supplies will be fed directly to the engine from sealed glass bottles and the displacing of the familiar tin will be an advantage in many ways since, apart from guaranteed measure, the contents can be seen and, incidentally, the shape of the bottle is such that it can be easily inverted into the oil filler of the engine, thus obviating loss by spilling, especially where such fillers are placed in awkward positions.

It is of interest to note the Company's exhibition of hydrogenation at Charing Cross Underground Station, a place, incidentally, one now instinctively associates with modern commercial enterprise in educating the public to at least some visual knowledge of commodities in everyday use which, in a vast majority of cases, are taken very much for granted. So much has been heard of, and written about, hydrogenation in the last few years without, to the lay mind, as yet any tangible expression, that the coincidence of a new synthetic hydrocarbon and the display of technique and issues involved, will do much to awaken interest in the untiring service that science renders to the community to-day.

\title{
Lessons in Visualisation from the Royal Academy
}

\section{By Dr. Vaughan Cornish}

CCENERY is defined as the appearance of a $\checkmark$ place from the picturesque point of view, and so, without pausing to consider what constitutes picturesqueness, we may note at once that scenery is an appearance. The science of scenery is, therefore, a science of appearances, and consequently the question whether a landscape painting is true to the facts can only be answered if we know how the physical surroundings are pictured through the agency of the eye.

There are three very different modes of picturing landscape; by the camera, by the representational school of painting, and by the imaginative school. Leaving the discussion of the last category for another occasion, let us now compare the rendering of the facts of scenery by the camera and by the school of painting hitherto dominant at the Royal Academy.

Even within the limits of monochrome, to which the camera is usually restricted, a clear photograph of a well-lit landscape is radically different from the natural picture. Not only the eye of the artist but also that of the ordinary man is selective. The natural picture of the landscape is not the sum of those features which we can see when we examine bit by bit the whole field of outlook, but a composition formed of that which we notice spontaneously. It may even be that in scenes which stir the emotions deeply, the proportion that remains unnoticed, that is to say mentally invisible, is greatest.

Largely on account of this selective action of the eye, and not merely on account of the vagueness of the image near the edge of the retina, the skilful composition of the landscape painter is in some important respects nearer than the photograph to the facts of scenery. It may be suggested in passing that the customary preference of the landscape artist for painting largely from memory, is not only on account of the troublesome variation of light in the actual scene, but also because memory is selective, and its partialities help to obliterate the inessential from the mental picture.

As an example of truth to Nature (in the wider sense) as exemplified in the school of landscape painting usually dominant at the Royal Academy, I may cite "The Shores of Clyde" (340) by 
Mr. Robert Houston. This is an entrancing picture of sea and sunshine, flowering gorse and sheep grazing, cottages of fisher folk by the shore (at the foot of the hill from which the scene is viewed), a rocky islet catching the light, and in the distance a range of mountain peaks suffused with the tranquil, atmospheric blue. A few clouds are floating high, and from above the field of sight, the sun streams down, casting a broad lane of light upon the rippling summer sea. It all seems so natural, and exactly as we recall the scenery of Scotland in its happiest mood. The descriptive title of the picture does not tie us to a particular view-point, and this is fortunate for the average man, who is apt to feel that some deception has been practised when he finds the natural features arranged otherwise than as he is accustomed to see them from a specified view-point. In this connexion it is well that scientific people should recall the fact that mathematicians exercise a license somewhat similar to that of the artist in the generalisation of geophysical facts. The tidal bore in the River Severn, for example, does not always conform to the type of wave to which mathematicians restrict the name, although the mathematical conception was largely based upon this local example.

The water-colour "Gate Crag, Grange, Westmoreland" (1039) by Mr. Harold Gresley, has a definitely locative title, but as I am not acquainted with the particular spot the question of composition does not obtrude, and I simply welcome a delightful rendering of the charm of the English Lakeland. A single-arched bridge spans a rapid stream beside which stand the simple, whitewashed houses that Wordsworth loved. The foliage of pleasant roundtopped trees diversifies the vale, and in the back- ground the steep fell-side stands in shadow, with white clouds half uncovered, half hidden by the rugged mountain crest.

The sympathetic rendering of such scenes is always welcome, but it must be confessed that our painters have been less alert than the cameramen in availing themselves of modern facilities of transport for extending their range of subjects. Such pictures as that by $\mathrm{Mr}$. Norman Wilkinson ("Territorials", 385) are as welcome as they are rare. The view, from an aeroplane, is of companion aeroplanes, backed by the piled domes of massive cumulus revealed in all their grandeur from a more advantageous point of sight than the ground provides.

When the man of science goes to the Royal Academy to learn what he can from the artist, it is well that he should not confine his attention to landscape, for pictures of interiors also convey lessons in visualisation. That of "The Library, Eaton Hall" (235), by Mr. Frederick W. Elwell shows a long gallery with the amplitude of dimension relatively to the human figure which is an outstanding advantage of the great country mansion. The perspective of such an interior satisfies certain faculties of the eye for which the natural landscape does not provide appropriate exercise. Moreover, the appointments of the room illustrate the fact that a well-furnished interior can provide more satisfaction for the eye in respect to diversities of texture than any natural scene. Here we have, skilfully painted, the glaze of pottery and porcelain, the glint of metal, the lustrous reflexion and transmission of glass vessels, and the polish of fine wood-work. Rich and varied as are these textures, it is the vase of flowers which brings the ultimate refinement of texture to the furnished interior.

\section{Obituary}

Sir JivanjI Modi, c.I.E.

$\mathrm{W}^{\mathrm{E}}$ E regret to record the death at Bombay of Sir Jivanji Jamshedji Modi, the widelyknown and highly esteemed Orientalist, on March 28 , aged seventy-two years. He was born on October 26, 1854, the son of the head priest of the Parsee Fire Temple at Colaba on the island of Bombay, and was educated at Elphinstone School and College. The studies to which he gave special attention, and in which he won a world-wide recognition as the foremost authority, were the origins, literature and teaching of Zoroastrianism, as well as the history of the Parsee community. For many years he was the secretary of the Parsee Panchayat in Bombay. He was one of the most active members of the Bombay Branch of the Royal Asiatic Society, which recognised his services to Oriental studies by the award of the Campbell medal in 1918. He was prominent in promoting the Oriental Research Institute at Poonah in memory of his friend, Sir Ramkrishna Bhandarkar, and did much work in connexion with the Cama Oriental Institute.
Sir Jivanji Modi's very considerable published contributions to scholarship for the most part appeared in the form of monographs, which were afterwards collected and republished in volumes such as his "Asiatic Papers", in four parts, "Anthropological Papers", also in four parts, "Memorial Papers", "Dante Papers", etc. He also wrote a history of the Parsees and published a number of translations from the Pahlavi.

His learning was widely recognised in both India and Europe; although it may be said without detraction from his scholarship that his commanding position in the world of Oriental studies was in some degree enhanced by his singleness of purpose and charm of character, which won the admiration and affectionate respect of all with whom he came into contact. He had long been a fellow of the University of Bombay, which conferred on him the degree of LL.D. in 1930. The Government of India made him an honorary correspondent of the Archæological Society in 1914 and conferred on him the title of Shams-ululama. He was made a C.I.E. in 1917 and knighted 